\title{
Magnetic Graphene-Based Sheets for Bacteria Capture and Destruction Using a High-Frequency Magnetic Field
}

\author{
Andri Hardiansyah ${ }^{1,2, \dagger}$, Ming-Chien Yang ${ }^{2,+} \mathbb{D}^{\mathbb{D}}$, Hung-Liang Liao ${ }^{2}$, Yu-Wei Cheng ${ }^{3}$, \\ Fredina Destyorini ${ }^{1}$, Yuyun Irmawati ${ }^{1}$, Chi-Ming Liu ${ }^{3}$, Ming-Chi Yung ${ }^{4}$, Chuan-Chih Hsu ${ }^{5, *}$ \\ and Ting-Yu Liu ${ }^{3, *(1)}$ \\ 1 Research Center for Physics, Indonesian Institute of Sciences, Tangerang Selatan 15314, Indonesia; \\ andri.hardiansyah@lipi.go.id (A.H.); fredinadestyorini@gmail.com (F.D.); irmawatiyuyun@gmail.com (Y.I.) \\ 2 Department of Materials Science and Engineering, National Taiwan University of Science and Technology, \\ Taipei 10607, Taiwan; myang@mail.ntust.edu.tw (M.-C.Y.); firstoneayu@hotmail.com (H.-L.L.) \\ 3 Department of Materials Engineering, Ming Chi University of Technology, New Taipei City 24301, Taiwan; \\ louischengblue@gmail.com (Y.-W.C.); U04187141@mail2.mcut.edu.tw (C.-M.L.) \\ 4 Department of Cardiovascular Surgery, Taiwan Adventist Hospital, and School of Medicine, National Yang \\ Ming University, Taipei 105, Taiwan; mcyung52@hotmail.com \\ 5 Division of Cardiovascular Surgery, Department of Surgery, Taipei Medical University Hospital, Taipei Heart \\ Institute, Taipei Medical University, Taipei 11031, Taiwan \\ * Correspondence: cchsu1967@hotmail.com (C.-C.H.); tyliu0322@gmail.com (T.-Y.L.) \\ + These authors contributed equally to this paper.
}

Received: 15 March 2020; Accepted: 29 March 2020; Published: 3 April 2020

\begin{abstract}
Magnetic reduced graphene oxide (MRGO) sheets were prepared by embedding $\mathrm{Fe}_{3} \mathrm{O}_{4}$ nanoparticles on polyvinylpyrrolidone (PVP) and poly(diallyldimethylammonium chloride) (PDDA)-modified graphene oxide (GO) sheets for bacteria capture and destruction under a high-frequency magnetic field (HFMF). The characteristics of MRGO sheets were evaluated systematically by transmission electron microscopy (TEM), scanning electron microscopy (SEM), zeta potential measurement, $X$-ray diffraction $(\mathrm{XRD})$, vibrating sample magnetometry (VSM), and $\mathrm{X}$-ray photoelectron spectroscopy (XPS). TEM observation revealed that magnetic nanoparticles (8-10 $\mathrm{nm}$ ) were dispersed on MRGO sheets. VSM measurements confirmed the superparamagnetic characteristics of the MRGO sheets. Under HFMF exposure, the temperature of MRGO sheets increased from 25 to $42{ }^{\circ} \mathrm{C}$. Furthermore, we investigated the capability of MRGO sheets to capture and destroy bacteria (Staphylococcus aureus). The results show that MRGO sheets could capture bacteria and kill them through an HFMF, showing a great potential in magnetic separation and antibacterial application.
\end{abstract}

Keywords: magnetic nanoparticles; reduced graphene oxide sheets; high-frequency magnetic field; bacteria capturing

\section{Introduction}

Accelerating research on carbon nanostructures led to the discovery of graphene. Structurally, graphene consists of a flat monolayer of carbon atoms tightly packed into a two-dimensional (2D) honeycomb lattice. Graphene is the basic fundamental structure for the derivative graphitic materials of all other dimensionalities including fullerenes, nanotubes, and graphite [1], and is also the thinnest and strongest material. Its charge carriers exhibit giant intrinsic mobility, have zero effective mass, and can travel for micrometers without scattering at room temperature [2]. Currently, graphene has 
attracted much attention in materials science [3], biotechnology [4], and bio-detection [5]. Significant development has been conducted for the utilization of graphene in bio-applications. Bio-applications of graphene and graphene oxide remain challenging and must be solved with effective collaborations through multiple disciplines, including biotechnology and nanotechnology [6,7].

Among the types of graphene-based materials, graphene oxide (GO)-based materials display a high specific surface area with an abundance of active oxygen-based functional groups including carboxylic, carbonyl, epoxy, or hydroxyl groups around their plane edge and basal plane structure $[8,9]$. These unique characteristics provide special sites for immobilization and functionalization by various moieties including polymeric materials such as polyethylenimine [10], chitosan [11], poly(lactic acid) [12,13], and inorganic nanostructures including gold [14], $\mathrm{TiO}_{2}$ [15], silver nanoparticles [16] and iron oxide nanoparticles [8,14]. Specifically, iron oxide nanoparticles exhibited magnetic characteristics that could be applied to various applications, especially for magnetic fluid hyperthermia [17], magnetic-based bio-separation [18], diagnosis and treatment of infections of bacteria [19], and inductive heating-based magnetic field exposure [20]. Currently, the combination of graphene-based materials and iron oxide nanoparticles have attracted attention due to their potential characteristics as graphene-based materials combined with magnetic nanoparticles [21]. The embedment of magnetite nanoparticles to the graphene sheets could restrict the graphene sheets from the agglomeration and restacking between each layer, promoting the stabilization of graphene layers and the enhancement of the surface area of the graphene sheets.

Currently, graphene-based materials have been extensively studied for their antibacterial activity against various types of bacteria such as E. coli, Colibacillus, S. aureus, or Candidia albicans [22-24]. Several features of graphene-based materials have been assessed to evaluate their antibacterial activity such as sheet size and concentration, surface area, surface roughness, hydrophilicity, dispersibility, and functionalization [25]. Bo Hu et al. have developed nanohybrid magnetic reduced graphene oxide composed of reduced graphene oxide, $\mathrm{Fe}_{3} \mathrm{O}_{4}$ and a bimetal core-shell of gold/silver ( $\mathrm{Au}-\mathrm{Ag}$ - $\mathrm{Au}$ ). They proposed the capture, separation, and destruction of Escherichia coli by using near-infrared photothermal treatment [26]. Rajni Singh et al. prepared nanocomposites of $\mathrm{GO} / \mathrm{Fe}_{3} \mathrm{O}_{4}$ and investigated their characteristics against several pathogenic bacteria and found that $\mathrm{GO} / \mathrm{Fe}_{3} \mathrm{O}_{4}$ as an effective bactericidal [8]. Moreover, various antibacterial mechanisms of graphene-based materials have been proposed, such as oxidative stress [27], membrane stress [27], electron transfer [28,29] or wrapping isolation [25]. Omid Akhavan and Elham Ghaderi have investigated the toxicity of graphene oxide nanosheets against $S$. aureus and E. coli. They proposed that the edges of the GO nanosheets and the charge transfer between bacteria have a significant effect to destroy the cell membrane of bacteria [30].

In respect to magnetic field exposures, a high-frequency magnetic field (HFMF) has been widely used as a tool to generate a magnetic field for hyperthermia applications [31,32]. Magnetic particles-based hyperthermia has been developed as a method that could potentially be applied to biomedical applications such as tumor therapy [33,34]. Previously, L.-Z. Bai et al. investigated the inductive heating property of $\mathrm{GO}-\mathrm{Fe}_{3} \mathrm{O}_{4}$. They found that the temperature of a physiological saline suspension containing GO- $\mathrm{Fe}_{3} \mathrm{O}_{4}$ hybrid could enhanced to $92.8^{\circ} \mathrm{C}$ during the AC magnetic field exposure [35]. Szabo et al. have prepared the magnetite/GO nanocomposites through the utilization of strong electrostatic interactions between the magnetite and GO particles [36].

This study will focus on the preparation and characterization of magnetic reduced graphene oxide (MRGO) and evaluate the antipathogenic behavior of MRGO in the exposure of HFMF. Polyvinylpyrrolidone (PVP) and poly(diallyldimethylammonium chloride) (PDDA) were used to modify the surface of GO and subsequently used as a substrate for the immobilization of iron oxide nanoparticles, denoted as MRGO. MRGO sheets were systematically characterized, including their structure, morphology, magnetic properties, and their interaction with bacteria. Specifically, the capturing capability was evaluated against Staphylococcus aureus as the model for pathogenic bacteria. The HFMF exposure was conducted to generate the inductive heating effects of MRGO sheets. To the best of our knowledge, there have only been a few reports related to the development of 
magnetic graphene and investigating its capture of bacteria and hyperthermia treatment simultaneously. Eventually, the combination of capturing and separating bacteria using an external magnetic field and killing them with HFMF-induced effects could potentially be applied in bio-separation and therapy.

\section{Materials and Methods}

\subsection{Materials}

Graphite powder ( $<20 \mu \mathrm{m}$, synthetic), fuming nitric acid $\left(\mathrm{HNO}_{3}\right), \mathrm{PVP}$, and PDDA (Mw $\left.<100,000\right)$ were purchased from Sigma Aldrich, St. Louis, MO, USA. Potassium permanganate $\left(\mathrm{KMnO}_{4}\right)$ and sulfuric acid $\left(\mathrm{H}_{2} \mathrm{SO}_{4}\right)$ were purchased from J.T. Baker Chemical Company, Philipsburg, NJ, USA. Hydrogen peroxide $\left(\mathrm{H}_{2} \mathrm{O}_{2}\right)$ was purchased from Acros. Hydrochloric acid $(\mathrm{HCl})$ was purchased from Scharlau, Scharlab, Barcelona, Spain. High-purity water purified by a Milli Q Plus water purifier system (Milipore, St. Louis, MO, USA), with a resistivity of $18.3 \mathrm{M} \Omega \mathrm{cm}$ was used in all experiments. All the chemicals were used without further purification.

\subsection{Preparation of Magnetic Reduced Graphene Oxide (MRGO)}

GO was prepared via modified Hummers method using graphite as the precursor material followed by the oxidation processes [37]. Surface modification of GO was conducted through the direct mixing with PVP and PDDA, simultaneously. Herein, PVP (average molecular weight 10,000 Da) was used to improve the aqueous dispersibility of GO [38]. Briefly, PVP (10 mg/mL) was added into the GO solution $(1 \mathrm{mg} / \mathrm{mL})$ as the dispersant. Furthermore, the above PVP-modified GO solution was mixed with $10 \mathrm{mg} / \mathrm{mL}$ of PDDA (the stock concentration: $0.2 \mathrm{~g} / \mathrm{mL}$ ) solution and $0.625 \mathrm{M}$ of $\mathrm{KCl}$ in the $20 \mathrm{~mL}$ of deionized water. The GO-PDDA solution was then stirred for $10 \mathrm{~min}$ at $90{ }^{\circ} \mathrm{C}$ and then stirred continuously for $12 \mathrm{~h}$ at $25^{\circ} \mathrm{C}$. The color change of the GO-PDDA solution confirms the reduction process of GO (brown) transformed to GO-PDDA (black) [37].

$\mathrm{FeCl}_{2} \cdot 4 \mathrm{H}_{2} \mathrm{O}$ and $\mathrm{FeCl}_{3} \cdot 6 \mathrm{H}_{2} \mathrm{O}$ were used as the initial precursors for the co-precipitation of $\mathrm{Fe}_{3} \mathrm{O}_{4}$ on the GO surface. Briefly, $\mathrm{FeCl}_{2} \cdot 4 \mathrm{H}_{2} \mathrm{O}(2.5 \mathrm{mmol})$ and $\mathrm{FeCl}_{3} \cdot 6 \mathrm{H}_{2} \mathrm{O}(5 \mathrm{mmol})$, with a ratio of $1: 2$, were briefly mixed homogeneously at room temperature [39]. The GO solution $(1 \mathrm{mg} / \mathrm{mL})$ was mixed with the previous solution and then the temperature was increased to $80^{\circ} \mathrm{C}$. Furthermore, ammonia solution (33\%) was added dropwise into the solution to initiate the coprecipitation of $\mathrm{Fe}_{3} \mathrm{O}_{4}$ onto the GO sheets. The final precipitation was denoted as MRGO (Figure 1a). 

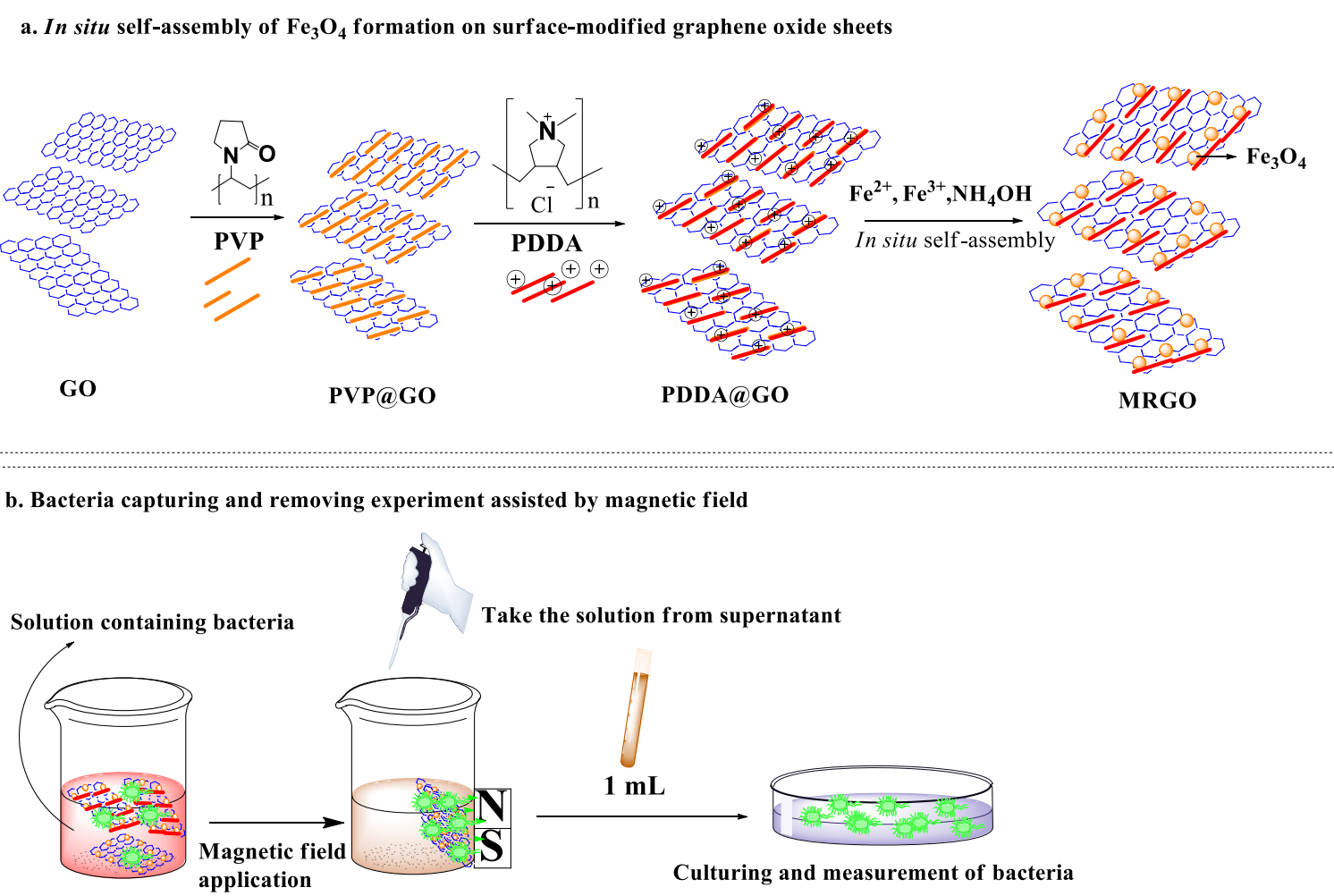

Figure 1. Schematic diagram of (a) magnetically reduced graphene oxide (MRGO) preparation and (b) bacteria capturing and separation assisted by magnetic field.

\subsection{Characterization}

The structure and morphology of MRGO were characterized by TEM (TEM-7650, Hitachi, Chiyoda-ku, Japan) at an acceleration voltage of $100 \mathrm{kV}$. The binding energy characteristics of GO and MRGO were investigated using X-ray photoelectron spectroscopy (XPS) (ESCALAB 250, Thermo VG Scientific, West Sussex, UK), equipped with $\mathrm{Mg} \mathrm{K} \alpha$ at $1253.6 \mathrm{eV}$ at the anode. X-ray diffraction (XRD) was conducted using a $\mathrm{D}_{2}$ Phaser BRUKER $X$-ray powder diffractometer to evaluate the phase of the material by scanning dried powder in the $2 \theta$ range of $20-80^{\circ}$ with $\mathrm{Cu} \mathrm{K}_{\alpha}(1.5406 \AA)$ radiation. The zeta potential of the graphene-based material before and after polymeric modification was determined through electrophoretic mobility measurements (Horiba Instrument). Vibrating sample magnetometry (VSM) (Lakeshore model 7400) was used to evaluate the magnetization of MRGO as a function of the magnetic field (Oe) at room temperature.

The bacteria capture by MRGO was observed using scanning electron microscopy (SEM) (JSM 5510, JEOL, Tokyo, Japan).

\subsection{Bacterial Culture Assessment and Bacteria Captured by MRGO}

Figure $1 \mathrm{~b}$ shows the schematic representation of the bacteria capturing experiments by the permanent magnetic field. The bacteria capturing capability of MRGO was evaluated against S. aureus (ATCC 43894). Briefly, frozen preserved stock was thawed at room temperature, $0.1 \mathrm{~mL}$ was then pipetted and streaked into a quadrant on a nutrient agar plate. Nutrient agar was composed of $6 \mathrm{~g}$ agar bacteriological (Agar No. 1) LP0011 powder mixed with $10 \mathrm{~g}$ DifcoTM LB (Luria-Bertani) Broth, Miller powder and diluted with $400 \mathrm{~mL}$ deionized (DI) water, and cultured at $37^{\circ} \mathrm{C}$ for $18-24 \mathrm{~h}$ to allow the formation of colonies. Afterward, a single colony was scraped with a loop and swabbed onto a $15^{\circ}$-slant medium (nutrient agar) which was then incubated at $37^{\circ} \mathrm{C}$ for $18-24 \mathrm{~h}$. After $18-24 \mathrm{~h}$ of culturing, at least $2 \mathrm{~mL}$ of $\mathrm{NaCl}$ solution $(1 \mathrm{wt} \%$ ) was added and stirred with a vortex mixer for $30 \mathrm{~s}$. 
After mixing, $1 \mathrm{~mL}$ of the solution was added into $9 \mathrm{~mL}$ of nutrient broth $\left(5 \mathrm{~g}\right.$ Difco ${ }^{\mathrm{TM}} \mathrm{LB}$ Broth, Miller powder/200 mL DI-water) and mixed with a vortex mixer, then $1 \mathrm{~mL}$ of the first nutrient broth solution was mixed into $9 \mathrm{~mL}$ of new nutrient broth. This process was repeated four times in a row. An aliquot of $1 \mathrm{~mL}$ of nutrient broth containing bacteria $\left(1 \times 10^{5}\right.$ colony forming unit $\left.(\mathrm{CFU}) / \mathrm{mL}\right)$ was added to a flask containing $1 \mathrm{~mL}$ MRGO, followed by shaking with a rotary shaker at $250 \mathrm{rpm}$ for $20 \mathrm{~min}$. The separation process was conducted by exposing the solution to an external magnetic field for $10 \mathrm{~min}$. After 18-24 h of culturing, the surviving bacteria were counted.

\subsection{Magnetic Inductive Heating (Hyperthermia) Experiment by HFMF}

Magnetic field-induced heat generation of MRGO was generated through HFMF exposure with a frequency of $15 \mathrm{KHz}$. Briefly, MRGO suspensions were subjected to the center of a copper coil in the HFMF apparatus for $20 \mathrm{~min}$. The temperature increases were recorded every minute using an alcohol thermometer.

\section{Results and Discussion}

\subsection{Physicochemical Characterizations}

Figure $2 a-2 b$ shows the TEM images of GO and MRGO, respectively. GO displays the lamellar structures with smooth and wrinkle surface. The diameter of GO is around a few micrometers (2-6 $\mu \mathrm{m}$ ) (Figure $2 \mathrm{a})$. Figure $2 \mathrm{~b}$ shows that the round-like shaped iron oxide $\left(\mathrm{Fe}_{3} \mathrm{O}_{4}\right)$ nanoparticles with a size of around 8 to $10 \mathrm{~nm}$ were embedded onto the surface of GO-based sheets. GO provides the host surface due to its high-surface area for the crystallization of $\mathrm{Fe}_{3} \mathrm{O}_{4}$ nanoparticles, which generated MRGO [21]. Moreover, the oxygen-based functional groups on GO can act as the nucleation sites for the coprecipitation of $\mathrm{Fe}^{2+} / \mathrm{Fe}^{3+}$ [21]. As shown in Figure 2b, the wrinkle structure of GO sheets disappear after the crystallization of $\mathrm{Fe}_{3} \mathrm{O}_{4}$ nanoparticles, which further confirms the reduction process of GO into magnetic reduced graphene oxide (MRGO). This is in accordance with the previous investigation by Bo Hu et al. [26]. Figure 2c indicates the selected area electron diffraction (SAED) pattern of GO, showing the hexagonal structure and the plane (1010) and (1210).
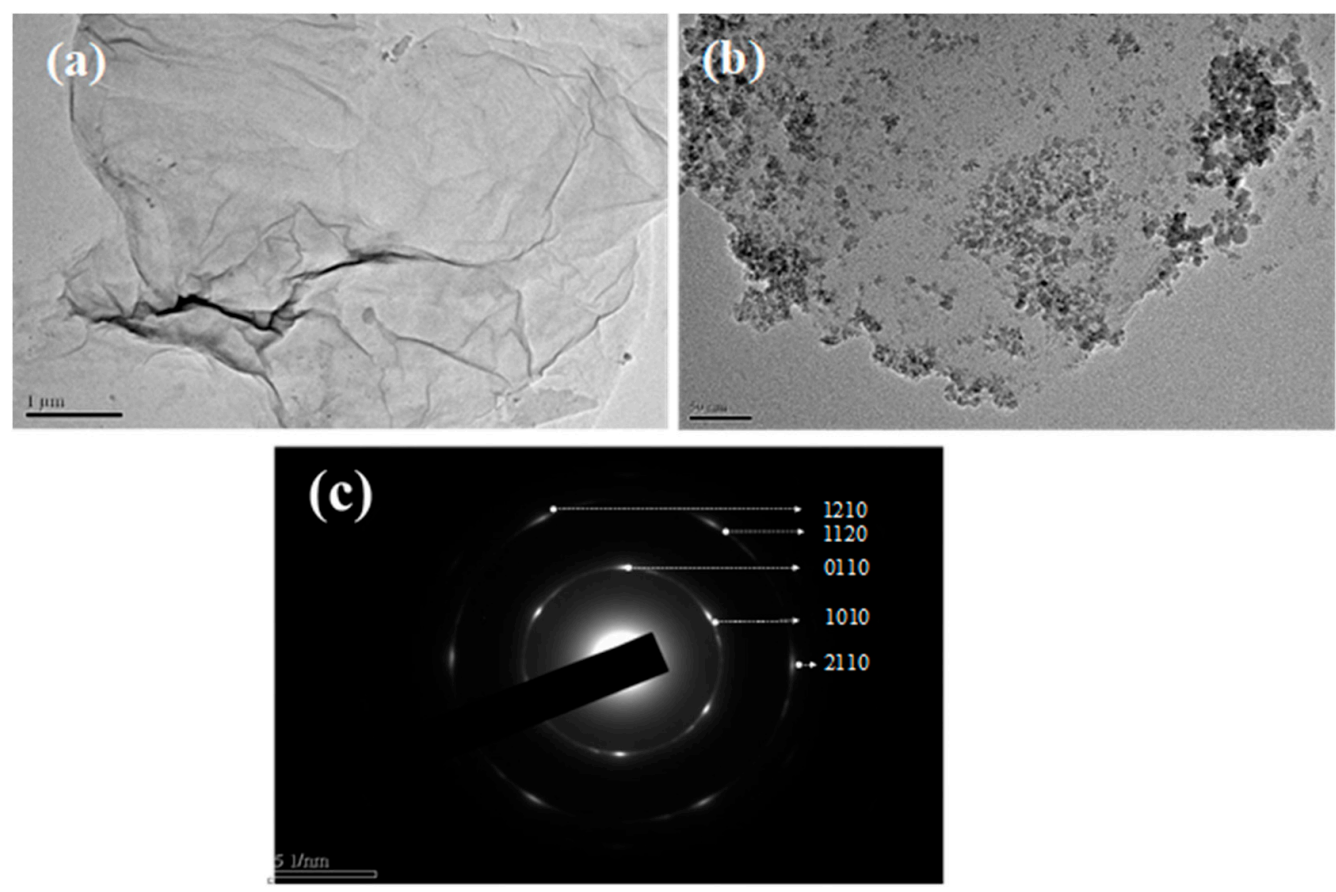

Figure 2. TEM image of (a) graphene oxide (GO) (scale bar: $1 \mathrm{~mm}$ ); (b) MRGO (scale bar: $50 \mathrm{~nm}$ ); (c) selected area electron diffraction (SAED) pattern of GO. 
Figure 3 shows the X-ray photoelectron spectra (XPS) of GO and PVP/PDDA-modified GO (reduced graphene oxide, RGO). The C-1s spectra of XPS showed that the graphite contained spectra of C-C at $284.01 \mathrm{eV}$ and $\mathrm{C}-\mathrm{OH}$ at $284.85 \mathrm{eV}$, respectively (Figure 3a). Further, the XPS spectra of GO (C-1s) characteristics peaks were found at C-C (285.16 eV), C-O-C/OH (287.17 eV), C=O (287.99 eV), and $\mathrm{O}-\mathrm{C}=\mathrm{O}(288.96 \mathrm{eV})$ (Figure $3 \mathrm{~b})$. The relative intensity of the oxygen-based functional group at the C-1s spectra of GO was higher than for graphite. The results confirmed the formation of oxygen-based functional groups, including hydroxyl, carboxylic, and carbonyl groups, on the basal or edge plane of $\mathrm{GO}$ as a consequence of the oxidation process on the graphite. Furthermore, the deconvolution C-1s XPS of GO-PDDA (RGO) spectra of C-C, C-O-C/OH, C-N, C=O, and O-C=O were observed at $284.71,285.40,286.01,286.82$, and $289.09 \mathrm{eV}$, respectively (Figure 3c). The presence of N-1s XPS spectra confirmed the immobilization of PDDA (nitrogen-contained polymer) on the surface of GO, as shown in Figure 3d.
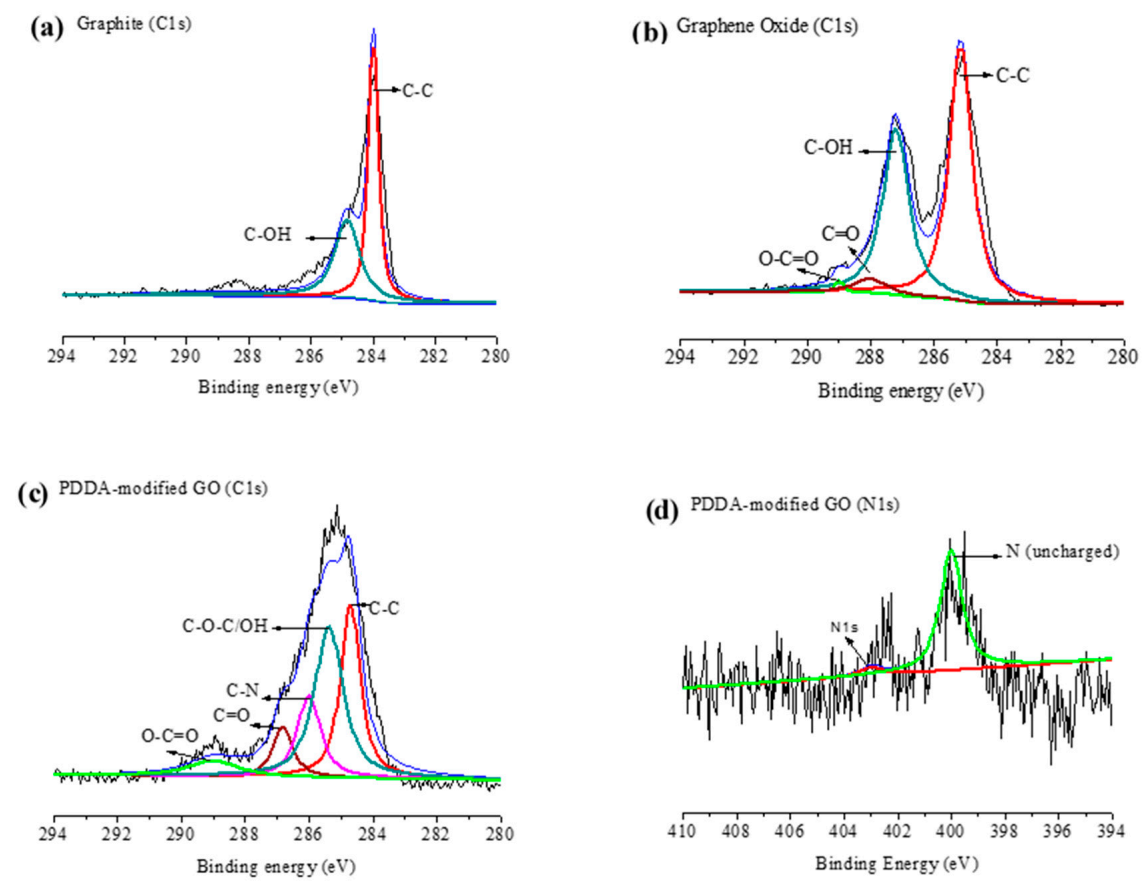

Figure 3. XPS spectra (C-1s) of (a) graphite, (b) graphene oxide (GO), (c) GO-poly (diallyldimethylammonium chloride) (PDDA) (RGO), and (d) XPS (N-1s) of GO-PDDA (RGO).

Figure $4 \mathrm{a}-\mathrm{c}$ shows the results of XRD pattern, VSM, and the zeta potential measurement. XRD patterns of $\mathrm{Fe}_{3} \mathrm{O}_{4}$ and MRGO show multiple peaks within the $2 \theta$ range of $20-80^{\circ}$ (Figure 4a). Six diffraction peaks at $2 \theta=30.1^{\circ}(220), 35.6^{\circ}(311), 43.3^{\circ}(400), 53.5^{\circ}(422), 57.2^{\circ}(511)$, and 62.9 $(440)$ were the characteristic peaks of the crystal plane, which was appropriated with the standard diffraction spectrum (JCPDS: 85436). This indicated the formation of magnetite $\left(\mathrm{Fe}_{3} \mathrm{O}_{4}\right)$ nanoparticles. The XRD pattern of MRGO shows a similar pattern to the pattern of $\mathrm{Fe}_{3} \mathrm{O}_{4}$ nanoparticles, indicating the formation of $\mathrm{Fe}_{3} \mathrm{O}_{4}$ nanoparticles on the graphene surface.

Figure $4 \mathrm{~b}$ shows the measured saturation magnetization of $\mathrm{MRGO}$ and $\mathrm{Fe}_{3} \mathrm{O}_{4}$ nanoparticles by VSM. The magnetization of MRGO was around $20 \mathrm{emu} / \mathrm{g}$, which was strong enough to separate the magnetic graphene from the aqueous solution. The decreasing saturation magnetization value of MRGO in comparison to $\mathrm{Fe}_{3} \mathrm{O}_{4}$ nanoparticles (around $60 \mathrm{emu} / \mathrm{g}$ ) could be due to the interference of the graphene-based material in the magnetic field exposure. As shown in Figure $4 \mathrm{~b}$, the field-dependent magnetization curves are reversible, which confirms that MRGO and $\mathrm{Fe}_{3} \mathrm{O}_{4}$ nanoparticles were superparamagnetic materials with zero coercivity and zero remanence. MRGO could disperse well in the aqueous solution in the absence of magnetic field exposure, which was generated due to the presence of an oxygen-based functional group on the surface of MRGO. Further, MRGO could 
be collected in the presence of magnetic field exposure (Figure $4 b$ ) for the magnetic separation of the microbes.

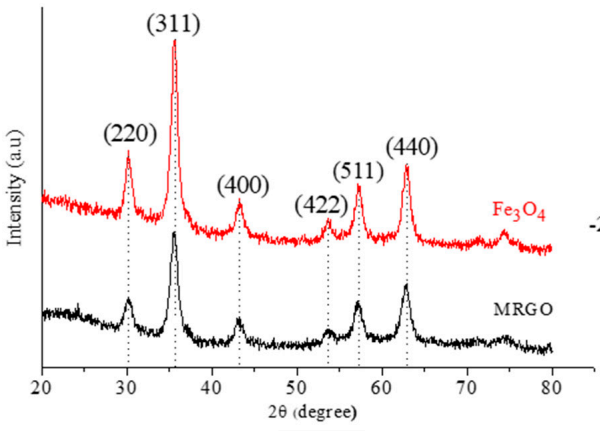

(a)

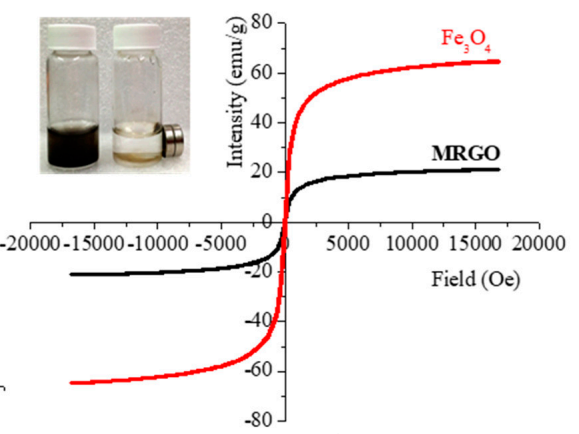

(b)

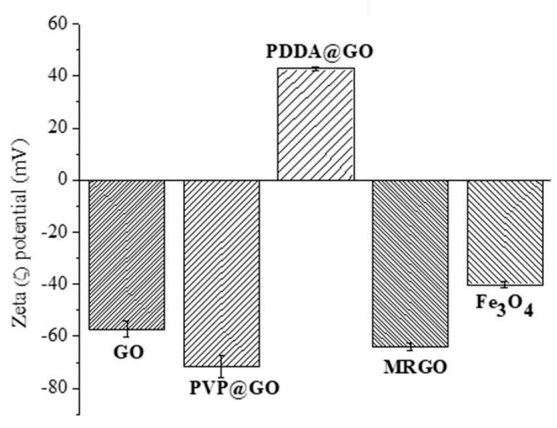

(c)

Figure 4. (a) XRD pattern and (b) VSM curves for $\mathrm{Fe}_{3} \mathrm{O}_{4}$ and MRGO; and (c) zeta potential for various as-prepared graphene and $\mathrm{Fe}_{3} \mathrm{O}_{4}$.

Figure $4 \mathrm{c}$ shows the zeta potential value of each component at $\mathrm{pH}$. The zeta potential of $\mathrm{Fe}_{3} \mathrm{O}_{4}$ nanoparticles is $-40 \mathrm{mV}$. This result might be caused by a number of hydroxyl groups (Fe-OH) [40]. GO exhibited negative charged of $-60 \mathrm{mV}$ suggesting the successful oxidation process of graphite through the formation of the negatively charged moiety (hydroxyl, epoxy and carboxyl) on the surface of GO. Surface modification of GO using PVP altered the zeta potential value to $-70 \mathrm{mV}$. This may be caused by PVP adsorbing onto the surface of the GO. A positive zeta potential value $(+42 \mathrm{mV})$ of MRGO was achieved after surface modification of PVP/GO by PDDA. PDDA could be tethered onto graphene sheets to develop a net positive charge due to the anchoring of nitrogen-based moiety on PDDA [41]. Eventually, the immobilization of $\mathrm{Fe}_{3} \mathrm{O}_{4}$ onto the PDDA/PVP/GO altered the net zeta potential value to $-65 \mathrm{mV}$, compared with the pristine $\mathrm{Fe}_{3} \mathrm{O}_{4}$ nanoparticles $(-40 \mathrm{mV})$. Thus, highly negatively charged MRGO also proved the high stability of MRGO due to the highly electrostatic repulsion among nanoparticles, which will prevent the aggregation.

\subsection{Capturing Capability of Bacteria}

Figure 5a shows the optical images of bacteria capturing activity toward the supernatant of $S$. aureus solution with various concentrations of MRGO. The supernatant of bacteria colony decrease indicates that more bacteria was captured. The results show that higher concentrations of MRGO will capture more bacteria. The optimal concentration of MRGO sheets is higher than $2.4 \mathrm{mg} / \mathrm{mL}$, which is enough to collect all of bacteria $\left(10^{5} \mathrm{CFU} / \mathrm{mL}\right)$ (Figure $\left.5 \mathrm{~b}\right)$. These results might be due to the higher density of functional groups and surface area of MRGO that could enhance the potential contact and interaction with $S$. aureus, followed by the settlement of bacteria on the surface of graphene-based materials [30]. From the point of view of antibacterial activity, graphene-based materials could damage or break the cell walls and cell membranes of bacteria through the interaction between the sharp 
edge of graphene-based materials and membranes of bacteria, causing the stress of the bacteria membrane [22,27,42]. This interaction could induce the leakage of RNA and transfer of charge [26]. Previous investigation proposed that the appropriate charge transfer between the bacteria and the more sharpened edges of the graphene-based materials could enhance the antibacterial activity of the graphene-based materials [30]. Another possible mechanism is the isolation of S. aureus from the surrounding medium during the incubation with the MRGO; therefore, blocking the consumption of nutrients for proliferation leads to the cells' death. In Figure 6, SEM images show that the morphology of MRGO sheets and bacteria ( . aureus) were captured in the surface of MRGO. A large surface to volume ratio of MRGO provided a space to capture bacteria for the interaction between the MRGO and the cell walls of bacteria. The bacteria were embedded onto the surface of MRGO. On the other hand, magnetic exposure could separate directly the captured bacteria on MRGO in the external magnetic field.

(a)

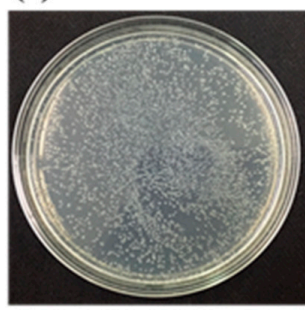

$0 \mathrm{mg} / \mathrm{mL}$

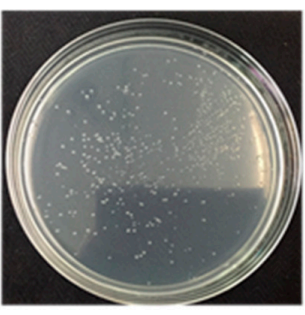

$0.4 \mathrm{mg} / \mathrm{mL}$

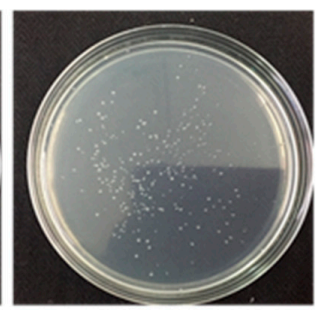

$0.8 \mathrm{mg} / \mathrm{mL}$

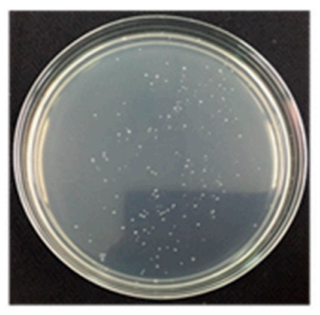

$1.2 \mathrm{mg} / \mathrm{mL}$

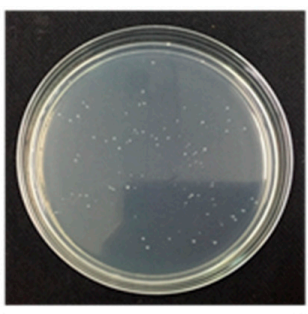

$1.6 \mathrm{mg} / \mathrm{mL}$

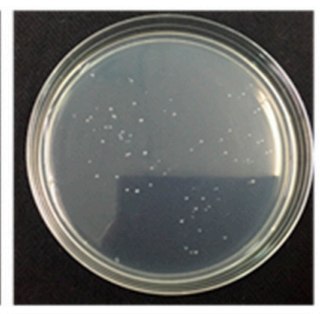

$2.0 \mathrm{mg} / \mathrm{mL}$

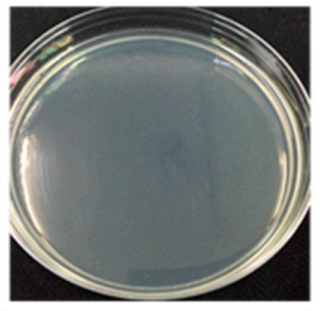

$2.4 \mathrm{mg} / \mathrm{mL}$

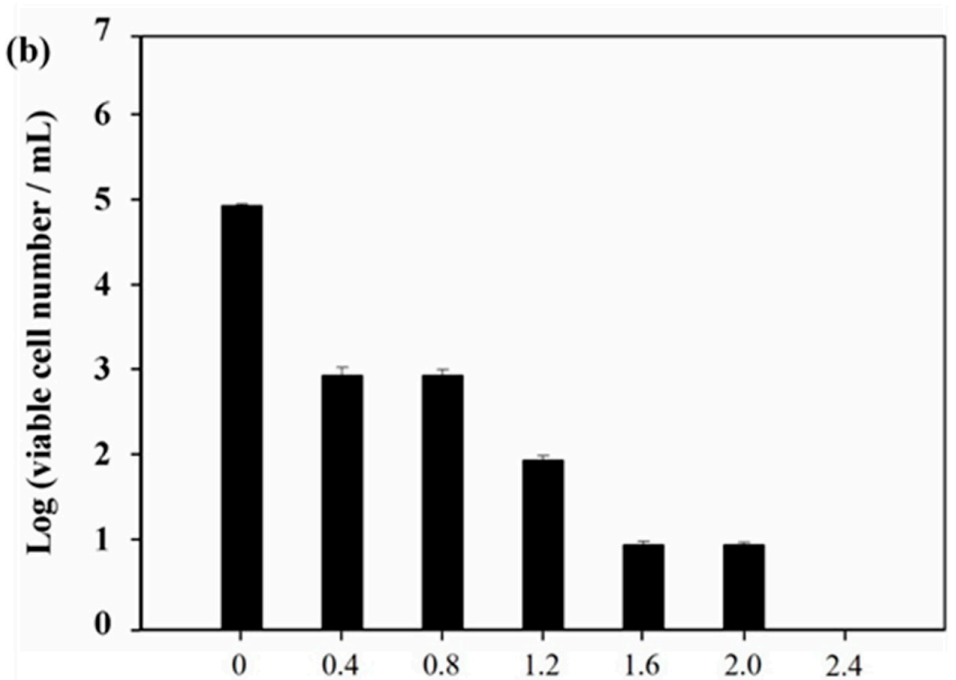

Concentrations of MRGO $(\mathrm{mg} / \mathrm{mL})$

Figure 5. (a) Capturing activity toward the supernatant of $S$. aureus $(105 \mathrm{CFU} / \mathrm{mL})$ solution with various concentrations of MRGO; (b) survival S. aureus numbers with various concentrations of MRGO. 


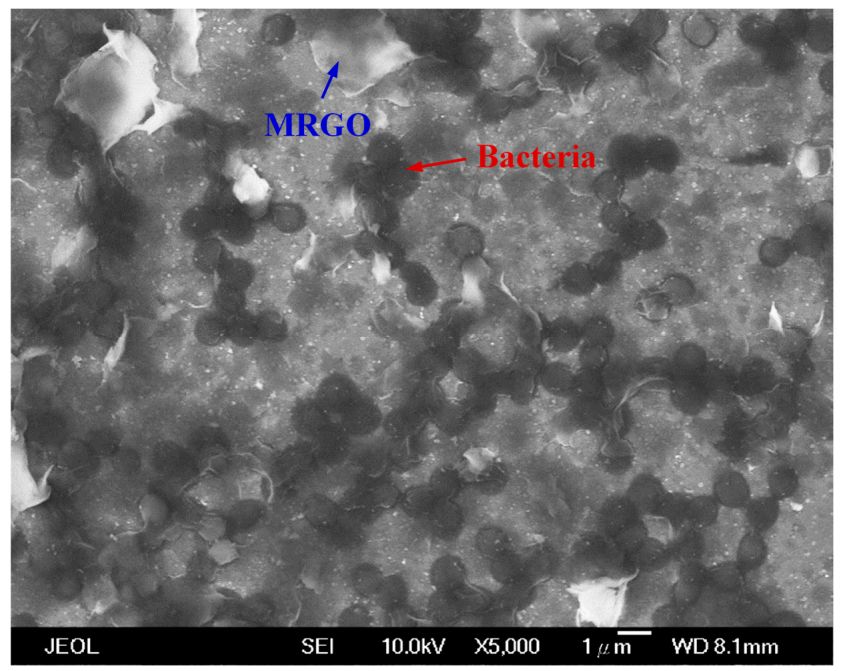

Figure 6. SEM image of MRGO sheets capturing bacteria (S. aureus) (scale bar: $1 \mu \mathrm{m})$.

\subsection{Hyperthermia Experiment and Bacteria Capturing and Removing Activity Assisted by HFMF Exposure}

Finally, HFMF was conducted to investigate the magnetic inductive heating of MRGO and to evaluate its capability for killing bacteria. Inductive heating is thermal energy induced from the hysteresis loss of ferrites and is dependent on the type of re-magnetization process in the HFMF [31]. Figure 7a shows the results of the inductive heating ability of GO and MRGO. GO cannot heat up during the exposure to HFMF and the temperature remained around $25^{\circ} \mathrm{C}$ (room temperature). Meanwhile, MRGO could increase in temperature up to $\sim 2{ }^{\circ} \mathrm{C}$, after the exposure to HFMF for 20 min. After HFMF was applied in MRGO, it could significantly decrease the colony number of bacteria, in comparison to that in GO (Figure $7 \mathrm{~b}$ ). The bacteria decrease from $10^{5} \mathrm{CFU} / \mathrm{mL}$ (control) to $\sim 10^{2}$ CFU/mL (MRGO) after exposure to HFMF for $20 \mathrm{~min}$, and only $0.1 \%$ of bacteria can survive. The calculated capability of MRGO to kill bacteria under HFMF is about $99.9 \%$ (Figure 7c). These results confirmed that the temperature increase in the MRGO was closely related to the incorporation of magnetic nanoparticles in the MRGO (Figure 7d). The generation of localized heat could disrupt the surrounding microbes [43].

(a)

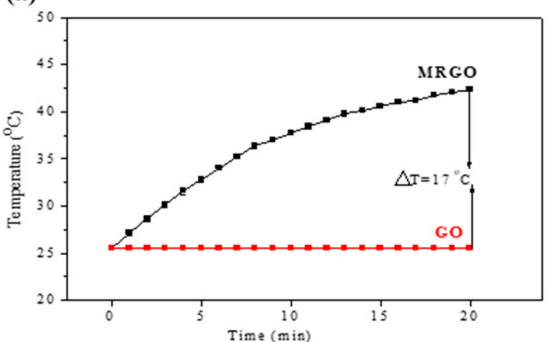

(c)

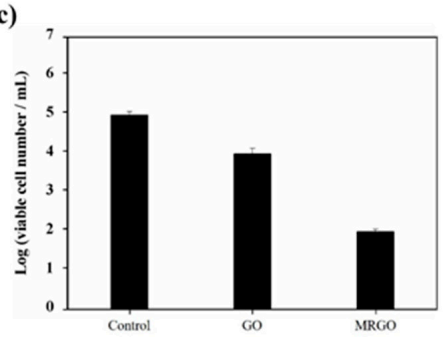

(d) (b)
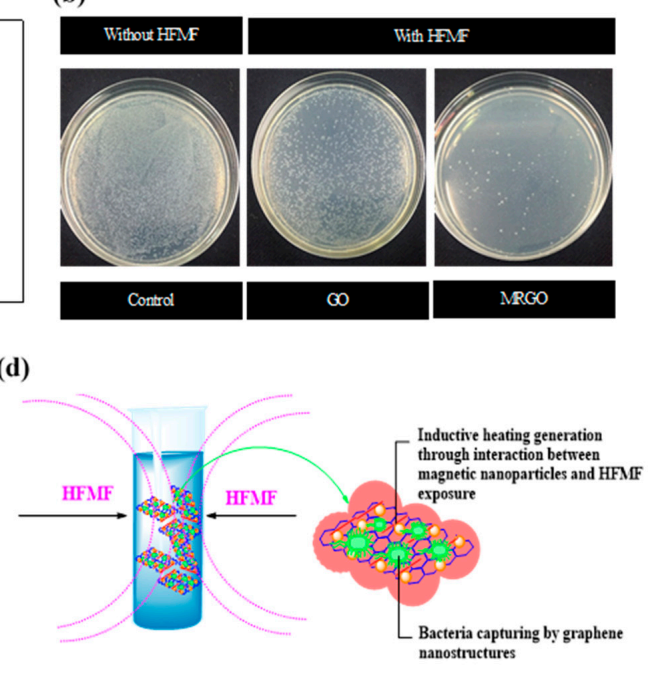

Figure 7. (a) Inductive heating temperature of GO and MRGO by high frequency magnetic field (HFMF); (b) bacteria activity with and without HFMF exposure; (c) survival S. aureus numbers of GO and MRGO by HFMF; (d) schematic diagrams of bacteria capturing activity and HFMF exposure. 


\section{Conclusions}

We developed an MRGO nanosheet through surface modification of GO using PDDA and coprecipitation of $\mathrm{Fe}_{3} \mathrm{O}_{4}$ nanoparticles onto the graphene sheets for capturing and separating microbes. TEM observation confirmed the formation of MRGO sheets, and $\mathrm{Fe}_{3} \mathrm{O}_{4}$ nanoparticles were able to disperse onto the graphene sheets. MRGO sheets could capture bacteria efficiently. When the content of MRGO reaches $2.4 \mathrm{mg} / \mathrm{mL}$, the bacteria $\left(1 \times 10^{5} \mathrm{CFU} / \mathrm{mL}\right)$ can be fully captured by MRGO. Furthermore, the hyperthermia effect, due to the localized heating, could be generated by MRGO through HFMF application and could kill the bacteria. These novel MRGO sheets have the potential to be developed for capturing, separating, and disrupting microbes.

Author Contributions: A.H., M.-C.Y. (Ming-Chien Yang), H.-L.L., C.-C.H., and T.-Y.L. are the main contributor of the paper. A.H., M.-C.Y. (Ming-Chien Yang) and H.-L.L. had conceived and designed the experiments. A.H. and H.-L.L. performed the experiments. A.H., Y.-W.C., F.D., Y.I., C.-M.L., C.-C.H., M.-C.Y. (Ming-Chi Yung) and T.-Y.L. contributed ideas and material analyses. A.H., M.-C.Y. (Ming-Chien Yang), H.-L.L., Y.-W.C., C.-C.H. and T.-Y.L. wrote and revised the manuscript. All authors have read and agreed to the published version of the manuscript.

Funding: This work was financially supported by Research Center for Intelligent Medical Devices of Ming Chi University of Technology, and the Ministry of Science and Technology of Taiwan (MOST 106-2221-E-131-006-MY3, MOST 108-2622-E-131-002-CC3 and MOST 108-2623-E-011-002-D).

Acknowledgments: Facilities were supported by Yuh-Lin Wang from the Institute of Atomic and Molecular Sciences, Academia Sinica (MOST 108-2639-M-001-003-ASP) and is gratefully acknowledged. We are also grateful to the staff of Technology Commons, College of Life Science, NTU for help with the transmission electron microscopy (TEM).

Conflicts of Interest: There are no conflicts of interest to declare.

\section{References}

1. Geim, A.K.; Novoselov, K.S. The rise of graphene. Nat. Mater. 2007, 6, 183-191. [CrossRef] [PubMed]

2. Geim, A.K. Graphene: Status and Prospects. Science 2009, 324, 1530-1534. [CrossRef] [PubMed]

3. Cao, R.; Wang, Y.; Chen, S.; Han, N.; Liu, H.; Zhang, X. Multiresponsive Shape-Stabilized Hexadecyl Acrylate-Grafted Graphene as a Phase Change Material with Enhanced Thermal and Electrical Conductivities. ACS Appl. Mater. Interfaces 2019, 11, 8982-8991. [CrossRef] [PubMed]

4. Wang, K.; Ruan, J.; Song, H.; Zhang, J.; Wo, Y.; Guo, S.; Cui, D. Biocompatibility of Graphene Oxide. Nanoscale Res. Lett. 2011, 6, 8. [CrossRef]

5. Abdelhamid, H.N.; Wu, H.-F. Multifunctional graphene magnetic nanosheet decorated with chitosan for highly sensitive detection of pathogenic bacteria. J. Mater. Chem. B 2013, 1, 3950-3961. [CrossRef]

6. Yang, Y.; Asiri, A.M.; Tang, Z.; Du, D.; Lin, Y. Graphene based materials for biomedical applications. Mater. Today 2013, 16, 365-373. [CrossRef]

7. Mao, H.Y.; Laurent, S.; Chen, W.; Akhavan, O.; Imani, M.; Ashkarran, A.A.; Mahmoudi, M. Graphene: Promises, Facts, Opportunities, and Challenges in Nanomedicine. Chem. Rev. 2013, 113, 3407-3424. [CrossRef]

8. Singh, R.; Sreedharan, S.; Karuppiah, S.; Singh, S. Enhanced bioactivity of $\mathrm{GO}-\mathrm{Fe}_{3} \mathrm{O}_{4}$ nanocomposite against pathogenic bacterial strains. Int. J. Nanomed. 2018, 13, 63-66. [CrossRef]

9. Chua, C.K.; Pumera, M. Chemical reduction of graphene oxide: A synthetic chemistry viewpoint. Chem. Soc. Rev. 2014, 43, 291-312. [CrossRef]

10. Yan, L.; Chang, Y.-N.; Zhao, L.; Gu, Z.; Liu, X.; Tian, G.; Zhou, L.; Ren, W.; Jin, S.; Yin, W.; et al. The use of polyethylenimine-modified graphene oxide as a nanocarrier for transferring hydrophobic nanocrystals into water to produce water-dispersible hybrids for use in drug delivery. Carbon 2013, 57, 120-129. [CrossRef]

11. Fan, L.; Luo, C.; Li, X.; Lu, F.; Qiu, H.; Sun, M. Fabrication of novel magnetic chitosan grafted with graphene oxide to enhance adsorption properties for methyl blue. J. Hazard. Mater. 2012, 215, 272-279. [CrossRef] [PubMed]

12. Pinto, A.M.; Moreira, S.; Goncalves, I.C.; Gama, F.M.; Mendes, A.M.; Magalhaes, F.D. Biocompatibility of poly(lactic acid) with incorporated graphene-based materials. Colloids Surf. B Biointerfaces 2013, 104, $229-238$. [CrossRef] [PubMed] 
13. Li, X.; Xiao, Y.; Bergeret, A.; Longerey, M.; Che, J. Preparation of polylactide/graphene composites from liquid-phase exfoliated graphite nanosheets. Polym. Compos. 2014, 35, 396-403. [CrossRef]

14. Shi, X.; Gong, H.; Li, Y.; Wang, C.; Cheng, L.; Liu, Z. Graphene-based magnetic plasmonic nanocomposite for dual bioimaging and photothermal therapy. Biomaterials 2013, 34, 4786-4793. [CrossRef]

15. Zhang, Y.; Pan, C. $\mathrm{TiO}_{2}$ /graphene composite from thermal reaction of graphene oxide and its photocatalytic activity in visible light. J. Mater. Sci. 2010, 46, 2622-2626. [CrossRef]

16. Liu, X.; Xu, X.; Zhu, H.; Yang, X. Synthesis of graphene nanosheets with incorporated silver nanoparticles for enzymeless hydrogen peroxide detection. Anal. Methods 2013, 5, 2298-2304. [CrossRef]

17. Sugumaran, P.J.; Liu, X.-L.; Herng, T.S.; Peng, E.; Ding, J. GO-Functionalized Large Magnetic Iron Oxide Nanoparticles with Enhanced Colloidal Stability and Hyperthermia Performance. ACS Appl. Mater. Interfaces 2019, 11, 22703-22713. [CrossRef]

18. Ito, A.; Shinkai, M.; Honda, H.; Kobayashi, T. Medical application of functionalized magnetic nanoparticles. J. Biosci. Bioeng. 2005, 100, 1-11. [CrossRef]

19. Xu, C.; Akakuru, O.U.; Zheng, J.; Wu, A. Applications of Iron Oxide-Based Magnetic Nanoparticles in the Diagnosis and Treatment of Bacterial Infections. Front. Bioeng. Biotechnol. 2019, 7, 141. [CrossRef]

20. Hardiansyah, A.; Huang, L.Y.; Yang, M.C.; Liu, T.Y.; Tsai, S.C.; Yang, C.Y.; Kuo, C.Y.; Chan, T.Y.; Zou, H.M.; Lian, W.N.; et al. Magnetic liposomes for colorectal cancer cells therapy by high-frequency magnetic field treatment. Nanoscale Res. Lett. 2014, 9, 497. [CrossRef]

21. Zubir, N.A.; Yacou, C.; Motuzas, J.; Zhang, X.; Diniz da Costa, J.C. Structural and functional investigation of graphene oxide- $\mathrm{Fe}_{3} \mathrm{O}_{4}$ nanocomposites for the heterogeneous Fenton-like reaction. Sci. Rep. 2014, 4, 4594. [CrossRef] [PubMed]

22. Kumar, P.; Huo, P.; Zhang, R.; Liu, B. Antibacterial Properties of Graphene-Based Nanomaterials. Nanomaterials 2019, 9, 737. [CrossRef] [PubMed]

23. Li, Q.; Yong, C.; Cao, W.; Wang, X.; Wang, L.; Zhou, J.; Xing, X. Fabrication of charge reversible graphene oxide-based nanocomposite with multiple antibacterial modes and magnetic recyclability. J. Colloid Interface Sci. 2018, 511, 285-295. [CrossRef] [PubMed]

24. Shen, J.; Shi, M.; Li, N.; Yan, B.; Ma, H.; Hu, Y.; Ye, M.J.N.R. Facile synthesis and application of Ag-chemically converted graphene nanocomposite. Nano Res. 2010, 3, 339-349. [CrossRef]

25. Hegab, H.M.; ElMekawy, A.; Zou, L.; Mulcahy, D.; Saint, C.P.; Ginic-Markovic, M. The controversial antibacterial activity of graphene-based materials. Carbon 2016, 105, 362-376. [CrossRef]

26. Hu, B.; Wang, N.; Han, L.; Chen, M.-L.; Wang, J.-H. Magnetic Nanohybrids Loaded with Bimetal Core-Shell-Shell Nanorods for Bacteria Capture, Separation, and Near-Infrared Photothermal Treatment. Chem. A Eur. J. 2015, 21, 6582-6589. [CrossRef]

27. Liu, S.; Zeng, T.H.; Hofmann, M.; Burcombe, E.; Wei, J.; Jiang, R.; Kong, J.; Chen, Y. Antibacterial Activity of Graphite, Graphite Oxide, Graphene Oxide, and Reduced Graphene Oxide: Membrane and Oxidative Stress. ACS Nano 2011, 5, 6971-6980. [CrossRef]

28. Pinto, A.M.; Gonçalves, I.C.; Magalhães, F.D. Graphene-based materials biocompatibility: A review. Colloids Surf. B Biointerfaces 2013, 111, 188-202. [CrossRef]

29. Gusev, A.; Zakharova, O.; Vasyukova, I.; Muratov, D.S.; Rybkin, I.; Bratashov, D.; Lapanje, A.; Il'inikh, I.; Kolesnikov, E.; Kuznetsov, D. Effect of GO on bacterial cells: Role of the medium type and electrostatic interactions. Mater. Sci. Eng. C Mater. Biol. Appl. 2019, 99, 275-281. [CrossRef]

30. Akhavan, O.; Ghaderi, E. Toxicity of Graphene and Graphene Oxide Nanowalls Against Bacteria. ACS Nano 2010, 4, 5731-5736. [CrossRef]

31. Liu, T.Y.; Hu, S.H.; Liu, K.H.; Shaiu, R.S.; Liu, D.M.; Chen, S.Y. Instantaneous drug delivery of magnetic/thermally sensitive nanospheres by a high-frequency magnetic field. Langmuir 2008, 24, 13306-13311. [CrossRef] [PubMed]

32. Kuo, C.-Y.; Liu, T.-Y.; Chan, T.-Y.; Tsai, S.-C.; Hardiansyah, A.; Huang, L.-Y.; Yang, M.-C.; Lu, R.-H.; Jiang, J.-K.; Yang, C.-Y.; et al. Magnetically triggered nanovehicles for controlled drug release as a colorectal cancer therapy. Colloids Surf. B Biointerfaces 2016, 140, 567-573. [CrossRef] [PubMed]

33. Dutz, S.; Hergt, R. Magnetic particle hyperthermia-A promising tumour therapy? Nanotechnology 2014, 25, 452001. [CrossRef] [PubMed]

34. Pankhurst, Q.A.; Thanh, N.T.K.; Jones, S.K.; Dobson, J. Progress in applications of magnetic nanoparticles in biomedicine. J. Phys. D Appl. Phys. 2009, 42, 224001. [CrossRef] 
35. Bai, L.-Z.; Zhao, D.-L.; Xu, Y.; Zhang, J.-M.; Gao, Y.-L.; Zhao, L.-Y.; Tang, J.-T. Inductive heating property of graphene oxide- $\mathrm{Fe}_{3} \mathrm{O}_{4}$ nanoparticles hybrid in an $\mathrm{AC}$ magnetic field for localized hyperthermia. Mater. Lett. 2012, 68, 399-401. [CrossRef]

36. Szabó, T.; Nánai, L.; Nesztor, D.; Barna, B.; Malina, O.; Tombácz, E. A Simple and Scalable Method for the Preparation of Magnetite/Graphene Oxide Nanocomposites under Mild Conditions. Adv. Mater. Sci. Eng. 2018, 2018, 11. [CrossRef]

37. Mevold, A.H.; Hsu, W.W.; Hardiansyah, A.; Huang, L.Y.; Yang, M.C.; Liu, T.Y.; Chan, T.Y.; Wang, K.S.; $\mathrm{Su}$, Y.A.; Jeng, R.J.; et al. Fabrication of Gold Nanoparticles/Graphene-PDDA Nanohybrids for Bio-detection by SERS Nanotechnology. Nanoscale Res. Lett. 2015, 10, 397. [CrossRef]

38. Huang, P.; Wang, S.; Wang, X.; Shen, G.; Lin, J.; Wang, Z.; Guo, S.; Cui, D.; Yang, M.; Chen, X. Surface Functionalization of Chemically Reduced Graphene Oxide for Targeted Photodynamic Therapy. J. Biomed. Nanotechnol. 2015, 11, 117-125. [CrossRef]

39. Liu, T.-Y.; Huang, L.-Y.; Hu, S.-H.; Yang, M.-C.; Chen, S.-Y. Core-Shell Magnetic Nanoparticles of Heparin Conjugate as Recycling Anticoagulants. J. Biomed. Nanotechnol. 2007, 3, 353-359. [CrossRef]

40. Hayashi, K.; Ono, K.; Suzuki, H.; Sawada, M.; Moriya, M.; Sakamoto, W.; Yogo, T. High-frequency, magnetic-field-responsive drug release from magnetic nanoparticle/organic hybrid based on hyperthermic effect. ACS Appl. Mater. Interfaces 2010, 2, 1903-1911. [CrossRef]

41. Wang, S.; Yu, D.; Dai, L.; Chang, D.W.; Baek, J.B. Polyelectrolyte-functionalized graphene as metal-free electrocatalysts for oxygen reduction. ACS Nano 2011, 5, 6202-6209. [CrossRef] [PubMed]

42. Zhan, S.; Zhu, D.; Ma, S.; Yu, W.; Jia, Y.; Li, Y.; Yu, H.; Shen, Z. Highly Efficient Removal of Pathogenic Bacteria with Magnetic Graphene Composite. ACS Appl. Mater. Interfaces 2015, 7, 4290-4298. [CrossRef] [PubMed]

43. Liu, T.-Y.; Chen, C.-L.; Lee, Y.-C.; Chan, T.-Y.; Wang, Y.-L.; Lin, J.-J. First Observation of Physically Capturing and Maneuvering Bacteria using Magnetic Clays. ACS Appl. Mater. Interfaces 2016, 8, 411-418. [CrossRef] [PubMed]

(C) 2020 by the authors. Licensee MDPI, Basel, Switzerland. This article is an open access article distributed under the terms and conditions of the Creative Commons Attribution (CC BY) license (http://creativecommons.org/licenses/by/4.0/). 